\title{
ABSTRACTS AND NOTICES FROM THE SCIENTIFIC AND TECHNICAL PRESS
}

\author{
Issued by the Directorates of Scientific Research and Technical Development \\ (Prepared by R.T.P.)
}

No. 8, APRIL, 1929

\section{Aircraft Engines, Fuels and Lubricants}

\section{Fuels}

The Oxidation of Hydro-Carbon. (Dumanois et Mondain-Monval Comptes Rendus, I $2 / 1$ I/28, p. 892.) (8.51/9918 France.)

To explain the phenomena of auto-ignition in engines, experiments were carried out with pentane-air mixtures in a sealed bomb. The initial pressure was about six atmospheres, temperature $20^{\circ} \mathrm{C}$. The temperature is raised by an electric heater, and the pressure recorded as a function of the temperature. For equal temperatures the observed pressures with fuel-air mixtures were considerably below those with fuel-nitrogen mixtures. In each case the ignition point is in the neighbourhood of $230^{\circ} \mathrm{C}$. The presence of tetraethyl lead causes a slight increase in pressure at temperatures above $120^{\circ} \mathrm{C}$, and an increase of $10^{\circ} \mathrm{C}$. to $20^{\circ} \mathrm{C}$. in the ignition temperature.

Ignition Testing Apparatus. (Motorwagen, No. 32, 20/11/28, p. 795.) (8.5I/ 9919 Germany.)

A commercial apparatus is described for testing the ignition point of fuels under pressure, the containing vessel being heated electrically. It is stated that once calibrated the results can be used to determine highest useful compression ratio.

The Dynamics of Ignition. (O. Klusener, V.D.I., Nov. 3rd, I928, p. I581.) (8.51/9923. Germany.)

Flame propagation was studied by means of indicator diagrams using a cylindrical bomb and heptane-air mixtures. The conclusion is reached that the mixture is normally ignited by means of a pressure wave, and that turbulence is insufficient to account for the high flame speeds observed in engines. Under special conditions this pressure wave ignition leads to detonation. Normal ignition and detonation differ only in degree,

Aero Engines for Commercial Aircraft. (P. Dumanois, La Technique Aeronautique, No. 83, September $15^{\text {th, }}$ 1928.) (8.51/9924 France.)

The author reviews the situation entirely from the fuel efficiency point of view. His remarks on detonation are especially interesting. There are three distinct types of ignition of a petrol charge :-

(I) A flame is started at the sparking plug and spread by turbulence of the mixture. This is normal combustion.

(2) The charge auto-ignites before the passage of the spark, usually at some local hot spot. This is pre-ignition, and causes serious over-heating of the engine and ultimate stoppage. 
(3) At some period subsequent to the passage of the spark the type of combustion changes. The flame is spread by molecular action instead of mechanically, and the mixture is said to detonate. Detonation is probably due to chemical activation either during the compression stroke or subsequent to the passage of the spark, and can be prevented by the presence of certain metallic dopes which appear to modify the activation of the charge. The charge may still auto-ignite, and there is evidence that the metallic dope may increase difficulties due to auto-ignition while suppressing detonation. The ideal engine fuel has to be equally free from both defects, and must rely entirely on turbulence to spread a flame which has been started at a definite moment by means of a spark. Mixtures of benzol, petrol and alcohol fulfil these requirements best.

The Temperature of Inflammation of Hydrogen-air Mixtures. (Pretre and Laffitte, Comptes Rendus, October 29th, I928; 9.763.) (8.51/9925 France.)

A dry hydrogen-air mixture was admitted suddenly into an evacuated Pyrex glass tube, heated electrically, and the temperature of visible flame on admission was noted. A series of experiments with ascending and descending temperatures determined the limiting temperature of inflammation. The results depended on vacuum in the Pyrex tube; with a 10 per cent. mixture and the high vacuum of I-IO,000 $\mathrm{mms}$. the temperature of inflammation was $455^{\circ} \mathrm{C}$, with a pressure of $10 \mathrm{mms}$. of mercury the temperature was $504^{\circ} \mathrm{C}$. The limits of inflammability are widened by pre-heating.

Flame Movement in Gaseous Explosive Mixtures. (O.C. de C. Ellis, Fuel, Vol. VII., No. I I, November, I928, p. 502.) (8.51/9926 England.)

Photographs show the propagation of a carbon-monoxide-oxygen flame through a closed tube with ignition from one end. The mechanism of flame vibration is followed, and is shown to be largely connected with the cooling effect of the walls. The article is to be continued.

The Velocity of Ignition of Liquid Fuels in Air. (H.' Mache, Sitzungsberichte, I928, No. 7, pp. 455-462.) (8.51/9927 Germany.)

Experiments determined the speed with which inflammation travelled along the free surface of various liquids. The vapour pressure of the liquid and the cooling produced by the surface over which the liquid is spread are important factors. The differences between liquids requiring a wick for combustion and those which do not are explained.

Flame Movement in Gaseous Explosive Mixtures. (O.C. de C. Ellis, Fuel, Vol. VII., No. Io, Oct., 1928, p. 449.) (8.51/9928 England.)

When no part of the flame surface is in contact with the wall of the tube, the rate of rise in pressure at any moment must be proportional to the mean pressure in the tube and to the total area of flame surface. When there is contact, the gross increment bears similar relations, being proportional to the pressure in the tube, and, nearly, to the number of flame surfaces ; the decrement, neglecting losses by radiation, is proportional to the pressure in the tube and to the total cooling surface, and it may be noted that the total cooling surface at the inception of the " second phase" increases with the number of ignitions, but less and less as the length of tube divided by the number of ignitions approaches equality with the bore of the tube. It would appear that in all cases there is a tendency to a net increment of pressure until the last flame surface expires; for, in general, the whole column of gas in the tube is brighter for the few centiseconds preceding and just following the expiration of the last surviving flame surface, as if this were always (as in some cases it is known 
to be) the period of minimum pressure. The duration of the total flame period; measured from the moment of ignition to the moment of expiration of the last surviving flame surface; tends to be less as the number of ignitions increases.

Acctylene as an Engine Fuel. (Dr. Lutz, Der Motorwagen, September ioth, 1928, p. 577 , ist article.) (8.51/9981 Germany.)

Experiments were carried out on a 4 -cylinder car engine, $90 \mathrm{~mm}$. bore, 99 $\mathrm{mm}$. stroke, compression ratio 3.96. Stable running with pure acetylene was obtained only within narrow mixture limits. Mixtures containing less than 3 per cent. by volume of acetylene were liable to backfire, and mixtures containing more than 5 per cent. to detonate. The explosion limits can be widened on the rich side by injecting water. A more effective process is to add a fuel of high latent heat to the acetylene. The results obtained with alcohol acetylene mixtures will be given subsequently.

Acetylene as an Engine Fuel. (Dr. R. Lutz, Der Motorwagen, No. 32, 20/11/28, pp. $777-783$, 2nd article.) (8.5 I/9982 Germany.)

Only weak acetylene-air mixtures can be employed without detonation; the permissible strength diminishing wth increasing speed. At each speed there are, usually two mixture strengths giving identical power, the weaker mixture being as prone to detonate as the richer one by reason of slower combustion. Autoignition and detonation can be reduced by injection of water or alcohol. Considerably less alcohol than water is required to avoid detonation, showing that the effect is not purely a thermal one and that the combustion of the alcohol affects that of the acetylene. The article is to be continued.

Some Flame Characteristics of Motor Fuels. (G. B. Maxwell and R. V. Wheeler, Industrial and Engineering Chemistry, Vol. XX., No. 10, October, 1928, p. 1041.) (8.514/10040.)

From the study of flame photographs of pentane, benzene and dopes the following conclusions were drawn :-

(I) The passage of a flame through a combustible mixture does not imply that the region through which the flame has moved is filled with exhaust products capable of no further chemical action.

(2) Although non-luminous, this region may be in a very sensitive state, still containing considerable amounts of chemical energy ready to be liberated if. a suitable impulse is provided.

(3) Combustion may be completed in this region by means of a pressure wave of relatively small amplitude. (Either initially produced at plug and reflected back or caused by vibrating burning of flame and flame arrest.)

(4) Such a completion of burning is practically instantaneous and is the cause of detonation in an engine.

(5) Detonation in an engine can be prevented by causing the reaction to become continuous in the wake of the flame.

(6) The region through which the flame has passed remains luminous, and any pressure waves set up before completion of combustion proper cannot liberate sufficient energy in this region to cause detonation.

(7) The effect of dope is to lengthen out the flame period, and make the flame of a pinking fuel (pentane) similar to that of a non-pinking fuel (benzene). In either case the region through which the flame has passed rapidly loses its available chemical energy, and the shock wave, if formed later, finds no energy to be released.

(8) Auto-ignition in front of the flame is not the cause of detonation. 


\title{
2 Lubricants
}

\author{
Motor Oil Characteristics. (S.A.E. Journal, October, I928, p. 380.) (8.41/9915 \\ U.S.A.)
}

There is a class of commercial lubricating oils with which engines can be cranked at low temperatures but which do not circulate until warmed up to or above the pour-point; and another class with which engines cannot be cranked at low temperatures but which would circulate if the engine could be started. A third desirable class would include oils with which engines can be cranked and which will also circulate at low temperatures.

\section{Thermodynamics}

Radiation from the Inside of a Circular Cylinder, Part II. (By H. Buckley, M.Sc., F.Inst.P. Abstr. Phil. Mag., No. 36, September, 1928, p. 475.) (8.57/9949 England.)

In a previous paper the effect of multiple reflexion from the walls of a uniformly-heated infinite cylinder in building up black-body radiation was considered. The method is now applied to the case of a finite uniformly-heated cylinder, and an approximate solution is obtained.

The brightness of the inside of a non-radiating cylinder illuminated by a uniform sky considered as a light well can be deduced.

The radiation from the inside of a uniformly-heated infinite cylinder with an infinite bongitudinal slit is obtained by the exact solution of an integral equation. The results show how closely a radiator of the type of Ives's primary standard of light approaches the ideal black-body radiator.

Mathematical Theory of Heat Storage. (W. Schmeidler, Z.A.M.M., Vol. VIII.,

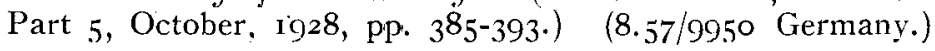

The discussion arises out of practical problems met with in the production of steel by the Siemens-Martin process, but the methods are of interest from the point of view of cooling problems, particularly air-cooled engines, and possibly hot wire anemometers.

Calculation of Temperature Distributions in Rotors of Electric Machines. (S. Bergman, Z.A.M.M., Vol. VIII., Part 5, October, 1928, pp. 402-413.) (8.57/995 I Germany.)

Mathematical methods are developed by following the flow of heat through an iron rotor and numerical results are tabulated. The methods are of general interest in connection with the flow of heat, and are not limited to the special problem.

\section{Dopes and Detonation}

Iron Carbonyl. (Chemical and Metallurgical Engineering, July, I928, p. 444.) (8.5 1 4/9917.)

Iron carbonyl under the trade name of "Motalin" is used as an antiknock compound. By the application of short-wave rays it yields $\mathrm{Fe}(\mathrm{CO})_{9}$, a reaction adaptable for making photographic copies. When ferric carbonyl is heated under special conditions " carbonyl iron" is formed, a very pure iron powder of high permeability, low hysteresis, and low eddy-current losses, suitable for magnetic cores and Pupin coils. Its purity and extreme subdivision render it suitable as a catalytic agent. When touched by a glowing match, it burns with an intense flame. 
Influence of Tetra-Ethyl Lead on the Detonation of Carburated Gas Mixtures.

(R. Duchene, Comptes Rendus, Part 4, July 23rd, 1928, pp. 200-203.) (8.5 I4/9920 France.)

Hexane-air mixtures at an initial temperature of $80^{\circ}$ were compressed adiabatically, compression ratio 4.4 , and fired by an electric spark. Mixture strengths varying from 8 to 12 per cent. by weight were examined either undoped or doped, with 5 per cent. tetraethyl. From a photographic study of the result of the explosions it is concluded that the lead dope influences the type of chemical reaction and prevents detonation when utilised in conjunction with a completely gasified fuel. The relatively large quantity of dope required in the case of a gras is explained by the absence of progressive concentration due to evaporation obtained when liquid fuels are present.

Action of Accelerators and Inhibitors upon the Oxidation of Liquid Hydrocarbons.

(T. E. Layng and M. A. Youker, Industrial and Engineering Chemistry,

Vol. XX., No. ro, October, I928, p. 1048.) (8.514/9921.)

The following conclusions were arrived at:-

(a) Hydroxidation theory of Bone is supported.

(b) No peroxide was detected on the oxidation of normal heptane.

(c) Results of Moreau and his co-workers depend on apparatus used.

(d) The oxidation of kerosene is accelerated by lead-ethyl at $200^{\circ} \mathrm{C}$.

(e) That of normal heptane is diminished by lead-ethyl at $160^{\circ} \mathrm{C}$.

Generally speaking, a successful dope should accelerate liquid oxidation and retard gas oxidation. Lead-ethyl owes its success to possessing both qualities.

Gaseous Explosions VI., Flame and Pressure Propagation. (J. V. Hunn and G. G. Brown, Industrial and Engineering Chemistry, Vol. XX., No. Io, October, I928, p. ro33.) (8.5 r4/9922.)

An analysis of coincident flame and pressure records of $\mathrm{CS}_{2}$, initially at atmospheric pressure, led to the following results :-

(I) After the flame has travelled a short distance a pressure crest of the order of 20 lbs. is set up behind the flame front.

(2) This crest is followed by a trough of approximately equal amount, and travels through the mixture with velocity of sound and is reflected backward and forward in the bomb.

(3) The passage of the wave through the flame can be followed by a brightening of the flame, and as many as 20 backward and forward passages can be traced out.

(4) When the flame has gone through the mixture, inflammation is at an end, but maximum pressure occurs at some later period.

(5) If a pressure wave overtakes the flame at a point where their velocities are nearly equal, a proper detonation wave may be set up.

Auto-Oxidation and Anti-Oxidation Properties of Antimony, Bismuth, Vanadium and some of their Compounds. (Charles Moreau, Charles Dufraisse and Marium Badoche, Comptes Rendus, No. 24, I0/12/28, p. Iog2.) (8.514/9929 France.)

The authors call attention to the fact that the same catalyzer may behave either as an accelerator or a retarder depending on the growing oxidation; on the other hand, two catalyzers of very similar chemical constitution may behave either as accelerators or retarders towards the same substance undergoing. oxidation. 
A Suggestion with Regard to Anti-Oxygenic Action. (K. C. Bailey, Chemistry and Industry, Vol. XLVIII., No. 2, I I/L/29, p. 35.) (8.514/9930.)

C. Moreau and C. Dufraisse have recently (Chemistry and Industry, I928, $47,819,848$ ) summarised the results of their important researches on antioxygens, notably that each molecule of the anti-oxygen prevents the oxidation of an enormously greater number of auto-oxidisable molecules; one molecule of hydroquinone prevents the oxidation of forty thousand molecules of acrolein, and similar results are obtained with benzaldehyde. In their well-known theory only those benzaldehyde or acrolein molecules which possess a certain minimum energy are capable of reacting with oxygen, and as these molecules occur in very small proportion at ordinary temperature, a very small number of hydroquinone molecules is capable of dealing with them.

The author, in criticism, points out that the activated molecules might circulate for a long time: without coming within the influence of molecules of anti-oxygen distributed uniformly through the volume. From his own experiments he concludes that about 90 per cent. auto-oxidation takes place at an inter-surface, and only about ro per cent. in the volume of the fluid. Surface reaction only is affected by the catalysers. The effectiveness of the catalyst is thus due to its presence in inter-surfaces. Auto-oxidation in the vapour phase is much more difficult to control by catalysts.

Synthetic Fuels. (A. W. Nash. A. R. Bowen, Journal of Institute of Petroleum Technologists, Vol. XIV., No. 69, pp. 643-65o, August, I928.) (8.514/993 I U.S.A.)

A survey of claims of previous years indicate many new results, some of which have not been substantiated by published experimental work.

The catalytic hydroxation of coal at high hydrogen pressures appears to be an important advance, and the pronounced effect of catalyst in this reaction has been shown.

The claims in the pyrolysis of methane are difficult to correlate with the fact that it has a tendency for breakdown into its element only, although its homogenes (ethene, propane and butane) are known to form higher aromatic hydrocarbons at moderately high temperatures.

\section{Carburation}

The Atomisation Produced by Carburettors. (F. N. Scheubel, Luftfahrtforschung, 26th June, 1928, p. 63.) (8.53/9932 Germany.)

The atomization of a typical carburettor was investigated photographically by means of spark photographs. The results obtained have been co-ordinated by means of the capillary wave theory. It is shown to be advantageous to make the throat of the choke parallel for some distance, and to place the fuel metering nozzle immediately in front of sudden expansions of the air stream cross section. There are numerous photographs and a bibliography.

Investigations on Atomisation with Spray Carburettors. (J. Sauter, V.D.I., No. 44, 3/1 I/28, pp. I 572-1 574.) (8.53/9933 Germany.)

The atomization is measured optically by observing the amount of absorption in a standard beam of light passing through the mixture. Various carburettors were compared, and it was found in every case that the atomization was insufficient at low air speeds. Although not capable of absolute measurement the plant described is considered as capable of yielding comparative data. 
Properties of Submerged Carburettor Jets Investigated at Purdue. (Automotive Industries, October 6th, T928, p. 480.) (8.53/9934 U.S.A.)

Experiments were carried out with benzol and the coefficient of discharge for various heads and types of orifices was determined. The results are plotted in terms of non-dimensional coefficients, and can thus be transferred to other liquids and jet sizes by suitable changes in the coefficients.

Theory and Design of a New Carburettor. (Masakiti Isikawa, Report of the Aeronautical Research Institute, Tokyo Imperial University, No. 43, September, I928, Vol. IV., 2.) (8.53/9935 Japan.)

The new carburettor consists of a choke tube of the Venturi type and a fuel diffuser, diamond-shaped in section, which is a substitute for the fuelspray nozzle of the simplest jet-in-tube carburettor. The choke tube slides axially and regulates the passage area of gas. A throttle valve may be entirely dispensed with.

Investigation on the flow of air through this carburettor was worked out mathematically.

A model carburettor was constructed on the basis of the mathematical analysis, and the test results agreed with the designed characteristic.

Another innovation is the method of compensating the effect of temperature on carburation. This problem has not been studied thoroughly hitherto, and only partial solutions were available. The effect is chiefly due to changes im density of air and fuel and inadequate regulation in the discharge-characteristic of the fuel-metering orifice with temperature. The solution was the use of a metering orifice of a discharge characteristic, whose variation with the temperature of fuel just compensated the corresponding changes in the density of air and fuel.

By analytical discussion and by experiment a simple form of orifice was. designed satisfying the required conditions. The method is applicable to other carburettor designs.

A Neu Method of Fuel Induction for Internal Combustion Oil Engines. (F) Rochefort, Comptes Rendus, No. I6, October I5th, 1928, pp. 638-640.) (8.53/9993 France.)

An auxiliary chamber communicates by a valve and channel with the main cylinder. During the induction stroke fuel is deposited in the channel. At the beginning of the compression stroke the valve opens, and the mixture which has been previously compressed flows at high speed from the auxiliary chamber into the main chamber, picking up the fuel in the connecting channel. As, compression proceeds the carburated mixture flows back into the auxiliary chamber, which is shut off by valve just before the spark passes. From this mechanical and gaseous injection good atomization without high pump pressures. is claimed.

\section{Heavy Oil Engines}

Tests with a Junkers' Motor Car Diesel Engine. (L. Richter, V.D.I., No. 44, 3/1 I/28, pp. 1569-1571.) (8.59/9983 Germany.)

The Junkers opposed piston lorry engine has been modified by increasing the diameter of the scavenging air piston. On ordinary gas oil the full load consumption was 3 ,200 grms. per b.h.p. hr., at quarter load 300 grms: just faintly visible. The speed of the engine is kept constant by a special governor over wide ranges of load, a useful feature in traffic. 
The Development of the Solid Injection Engine. (Symposium of papers read at the general meeting of the V.D.I. at Essen, 1928. V.D.I., I5th September; 1928, p. 1279.) (8.59/9984 Germany.)

In solid injection Diesel engines the after burning of the fuel gives rise to excessive heat transfer to the walls, and a reduction in fuel economy and various devices are described for reducing it to a minimum, essentially by directing fresh air into the neighbourhood of the injection nozzle and removing the exhaust products as fast as possible. The two stage ignition engine with nozzle injection into the throat gives a fair approximation to these requirements.

In the coal dust injection engine, the coal has to be very finely pulverised, and the metering presents difficulties. Injection takes place early in the compression stroke against small pressures. A whole stroke is available for the preparation of the fuel, permitting comparatively high speeds. An engine of this type has been in operation for quite long periods, and, subject to overcoming lubrication difficulties caused by the accumulation of ash in the lubricating oil, it may prove a practicable design.

\section{Junkers' Oil Enqine for Aircraft. (La Conquete de l'Air, I/11/28, p. 504.) (8.59/9985 Germany.)}

An illustration is given of the 6-cylinder opposed piston oil injection aeroengine shown by Junkers at Ila, Berlin. The engine possesses two parallel crankshafts which are driven through intermediate spur gears. One of these gears operates the propeller. Further details are not given, but the estimate of performance, 700 h.p. for $800 \mathrm{kgms}$. weight, is considered optimistic. Junkers lorry engine, now in production, only develops $40 \mathrm{~h} . \mathrm{p}$. for $370 \mathrm{kgms}$. weight.

Exhaust Temperature as Load Index for Oil Engines. (By E. C. Magdeburger, Member, Journal of the American Society of Naval Engineers, p. 496.) (8.59/9989 U.S.A.)

Experiments carried out on a Deutz solid injection engine show that in general the B.M.E.P. increases with the exhaust temperature up to a limit of about $500^{\circ} \mathrm{C}$, above which the engine runs badly, and the M.E.P. decreases. A table of exhaust temperature, B.M.E.P. and speed is given, from which may be determined:-

(a) The total shaft power developed at any. engine speed;

(b) The distribution of load on individual cylinders;

(c) Whether the unequal load distribution is dangerous to any of the cylinders ;

(d) Maximum power output at any engine speed;

(e) Maximum engine speed for any desired M.E.P. or maximum M.E.P. for any desired engine speed;

(f) Best operating conditions with least heat load when both engine speed and brake M.E.P. may be varied. meters.

The instruments required are much simpler than either indicators or torsion

The Precompression Chamber Diesel Engine. (V.D.I., Vol. LXXII., No. $3^{6}$, September 8th, I928, pp. I 24I-I 248.) (8.59/9998 Germany.)

A mathematical theory of the air flow in combustion chamber and ignition pot is given with an expression for the distribution of turbulence throughout the working stroke. The smaller size two stage ignition engine is considered in comparison with the plain solid injection type. It is less sensitive to fuel composition, and will operate satisfactorily over a wide speed range. 
The Daimler-Benz Oil Engine. (Der Motorwagen, No. 23, August 2oth, 1928, p. 532.) (8.59/1000I Germany.)

The engine has six cylinders in line of bore, 105 and stroke $65 \mathrm{~mm}$. at 13,000 r.p.m. it gives about 80 b.h.p. with maximum M.E.P. about 1oo lbs./ sq. in. at 800 r.p.m. for a fuel consumption of 200 grammes per b.h.p. hr., and engine weight $9 \mathrm{kgms}$. per b.h.p. The suitability of two stage ignition for high speeds outweighs the inherent increase of fuel consumption. The lower fuel pressures throw less load on the Bosch jerk pump installation which has ports cut into the hollow pistons serving as inlet valves. The delivery valve is spring loaded, and rotation of the piston alters the timing of the inlet valve and the delivery.

New Methods of Using Fuels of High Boiling Point in Internal Combustion Engines. (Ing. H. Ellerbusche, Der Motorwagen, No. 24, August 3 Ist, I928, pp. 55 $1-55^{8}$.) (8.59/10002 Germany.)

A vaporiser consisting of a cast iron sleeve fitting into a recess in the cylinder walls has a diaphragm which obstructs the passage of the gas from the valves to the piston head. The heavy fuel entering through the inlet valve is caught in the tray of the vaporiser, which reaches a high temperature, causing the fuel to evaporate, and produces turbulence in the air stream promoting combustion. Tetraline and mixtures of benzol, tetraline and anthracene oil gave satisfactory results. Crankcase dilution of the lubricating oil was prevented, and the engine could be operated without preheating of the air.

Experimental Diesel Engines. (A. Turner, Inst. Naval Architects, Trans. 70, pp. 60-74, Disc. 74-85, I928.) (8.59/10003 England.)

The Admiralty Engineering Laboratory, West Drayton, has investigated the high-power Diesel engines of minimum weight and bulk suitable for driving marine propellers of the following types:- Single-acting and double-acting engines working on the four-stroke cycle and opposed piston; stepped piston and double-acting engines working on the two-stroke cycle. Details of dimensions and general performance are given for two engines built to the designs of the laboratory and three engines of proprietary design, results of supercharging through the induction pipe and by supplementing the air blast. The difficulties encountered are faulty combustion, thermo-mechanical effects, and mechanical wear. Special indicator connections were made to investigate the gas pressures behind the piston rings, and several indicator diagrams are given showing the pressures recorded with different arrangements of the rings. The test results and conclusions are numerous.

Effect and Avoidanoe of Leaky Exhaust Valves in Diesel Engines. (O. Dinkela, Siemens Zëits, 8, pp. $3^{82-384}$, June, 1928, Science Abstracts, Section B, Vol. XXXI., Part I I, p. 576.) (8.59/10004 Germany.)

With a leaky exhaust valve, caused by particles of carbonised oil settling on the surface, a smaller amount of air is drawn in, the piston exercises less pressure, the regulator causes more oil to be drawn into the cylinder, ignition is delayed, and the exhaust temperature increased. An unsuitable mixture produces smoke in the exhaust and an increased tendency to carbonisation in the exhaust valve. The other cylinders may then draw an excessively rich mixture to compensate for the loss of power. Pyrometers in the exhaust offer the easier means of detecting this defect, and $\mathrm{CO}_{2}$ meters should also be introaluced. 
Lorry Diesel Engine made by Deutz. (Motorwagen, 30/11/28, p. 807.) (8.59/10037 Germany.)

The Deutz Diesel is a solid injection two stage ignition engine, with the ignition pot of the combustion chamber displaced to one side to facilitate the placing of the valve, and cooling of the head. The stroke of the fuel jerk pump is varied by a cam. At low speeds a spring coupling with ratchet between pump and engine causes the cam to rotate quickly with improved atomisation. At high speeds the ratchet is thrown out of action by centrifugal force. The fuel consumption is below $200 \mathrm{gr} . / \mathrm{b} . \mathrm{h}$.p. hr. between half and full load. The engine is not sensitive to the type of fuel. It is started by electric drive without compression, and the cylinders are brought into action one at a time.

Coal Dust Engine. (R. Pavolikowski, Der Motorwagen, 2oth July, 1928, p. 450.) (8.59/10038 Germany.)

The Kosmos Machine Works of Goerlitz, Germany, have converted to work on pulverised coal, a Diesel engine of $16 \frac{1}{2}$ in. bore, 25 in. stroke, singlecylinder, four-stroke cycle, rated 80 b.h.p. at I6o r.p.m., which for twelve years has operated on coal and other solid fuels. Numerous nozzles were tried. The charge of pulverised coal is drawn into a special chamber by suction, which is then sealed to the outside, and the coal is forced by excess pressure into the compressed combustion air in the cylinder, where it ignites at a pressure of 440 lbs. per sq. in. With a suitable design of combustion chamber the particles of ash remain in suspension and are expelled with the exhaust. To prevent ash from affecting the lubrication, clean air at 880 lbs. per sq. in. is admitted between the piston rings, restricting wear to the upper part of the cylinder. The pulverisation is as fine as for furnace firing, and finer when the ash content is high. Hard coals can be employed, but give better results if ignited with gasoline or activated coal. The maximum output was $\mathrm{r} 20$ b.h.p. originally, and I Io b.h.p. was obtained after three years' running. The maximum I.M.E. ranged from 162 to 167 lbs. per sq. in., the pressure at the end of the expansion being $53 \mathrm{lbs}$. per sq. in. T.wo photographs and two indicator diagrams are reproduced.

The Opposed Piston Junkers' Diesel Engine for Motor Cars. (R. Conrad, Motorwagen, September 3oth, 1928, p. 645.) (8.59/10039 Germany.)

The crankshaft has a middle bearing on the circular web of the third throw, giving the much shortened construction essential, since even the two-cylinder type requires a six throw shaft. The fuel consumption is stated as $44 \mathrm{lbs}$. per b.h.p. hr. at 600 to 200 r.p.m., and 530 to 50 b.h.p., M.E.P. I Io lbs. per sq. in. at 600 r.p.m., 95 lbs. at I 200 r.p.m.

Abstractor's Note.-A Junkers Diesel of this type built under license took part in the recent French competition for lorries using heavy oils. It was stated that the lorry was slow and the exhaust cloudy.

\section{Engine Design}

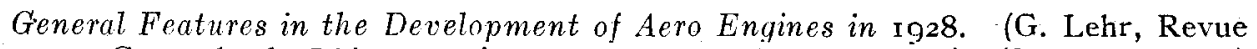
Generale de L'Aeronautique, Part 9, 1928, pp. 57-99.) (8.999 I France.)

Unless the rated output can be maintained for at least 50 hours continuously an engine is not fit for service conditions. The weight/h.p. ratio alone can be very misleading, and the high figure for certain racing engines is no sign of development of service engines as a whole. The latter have not shown much progress during the year. There is a tendency to improve performance by increasing the revolutions per minute and fitting a reduction gear. The high speed engine is essentially a short stroke engine, and this accounts for 
the success of the Napier Lion. Crankshaft troubles have been overcome by increasing the diameter of the shaft. Extensive drilling keeps the weight of such a shaft down and the fitting of thin webs gives increased bearing surface without lengthening the crankcase unduly. Such crankshafts, although stiff under load conditions, require careful handling when being machined, as the webs are easily deformed by transverse loads. The necessity of rigidity in the crankcase is fully realised, and in water-cooled engines the practice of making the crankcase encircle a considerable portion of the cylinder is becoming general. To reduce weight pistons are made as short as possible, and the general use of light alloys for moving parts is being considered. By careful piston ring construction the oil consumption has been reduced to the low figure of $5 \mathrm{gr}$. per h.p.h. Progress has been made in the reduction of magneto weights, notably in the American Spitdorf magneto, which has two independent windings and one rotating element. Fire risks can be reduced by the use of fuels of higher flash point, such as "white spirit," a paraffin fraction distilling between $130^{\circ}$ and $180^{\circ} \mathrm{C}$. The use of this fuel has been restricted by high price and low quality production. The fire risks could be further reduced by using heavy fuels with complete departure from present engine design. Such engines with a performance equalling that of existing carburettor engines will not be available for several years.

The New Walter Aero Engine. (Castor, Flugwoche, Part 7, 1928, p. I8In) (8.6/9986 Czecho-Slovakia.)

The firm of Walter (Prague, Czecho Slovakia) has developed a new 7 cylinder radial of approximatedy 300 h.p.-bore I $35 \mathrm{~mm}$., stroke I7o mm., compression ratio 6-1, maximum r.p.m. I $85^{\circ}$, normal output 340 h.p., fuel consumption 225 grms. per b.h.p. hr., oil consumption 18 grms. b.h.p. hr., weight including airscrew hub $248 \mathrm{kgms}$.

The engine has passed stringent type tests.

\section{Rotary Valve Petrol Engine. (L'Industria, Vol. XLII., p. 227, Italy.) (8.6/9987 Italy.)}

The first part of the article gives a detailed analysis of the kinematics of the rotary valve of the Bournonville type. It discusses a single-ported valve as a basis-running at half engine speed-and extends the results to the tripleported type, running at one-sixth engine speed. Numerous diagrams are given. The second part discusses constructional details, and describes an Italian singlecylinder motor-cycle engine. The Barison type, using a slightly conical valve (apex angle $3 \mathrm{deg}$.), is mentioned, and a detailed description is given of the Minerva-Bournonville engine, which is a three-ported engine of $1,99 \mathrm{I} \mathrm{cu} . \mathrm{cm}$. capacity with a compression ratio of 5.2 yielding 35 h.p. at 3,000 r.p.m.

Theory of the Dynamic Vibration Absorber. (J. Ordmondryod and J. P. den Hartog, Mech. Eng., May, 1928, No. 5, p. 49.) (8.22/9973 U.S.A.)

"Vibration Absorber" is a small vibratory system tuned to the operating frequency of a larger machine, and attached to it at a suitable point. The absorber, without damping, annihilates vibrations of its own frequency comi pletely, but creates two other critical speeds in the system and is suitable only for constant speed machinery. When damping is introduced, the absorber constitutes a simple and effective means of diminishing the vibrations of a variable speed machine. An analysis of its operation in simple cases with and without damping is given, tests made on a model are described, and actual applications are discussed. 
Selection of Ball Thrust Bearings for Aircraft Engines. (Chas. W. Rauch, Aviation Engineering, October, I928, p. I3.) (8.23/9990 U.S.A.)

Thrust formulæ derived from boat propellers are useful in selecting airscrew thrust bearings. The thrust of an airscrew on the Wright Whirlwind is 600 lbs. in level flight, and the thrust bearing evidently has a generous safety factor, as no failure or serious wear has been reported. Inspection of a Pacific Air Transport engine showed perfect condition after I,569 hours or 150,000 miles.

Improvement in the Mechanical Efficiency of Internal Combustion Engines by the Employment of Unsymmetrical Pistons. (A. Eteve, French Air Ministry Technical Bulletin, No. 50, September, 1928.) (8.24/9996 France.)

It is proposed to balance the side thrust of the piston due to the obliquity of the connecting rod by fitting the piston with an inclined head, in this way the gas forces can be made to balance to a large extent the side thrust. The difficulty is to provide a satisfactory gas seal round the inclined surface of the head, which prevents any leakage destroying the gain oblique piston rings. Figures show an apparent increase in power of 5 per cent., but the experimental accuracy is hardly of this order.

New Russian Air-Cooled Engine. (Le Document Aeronautique, No. 26, May, 1928, p. Io8.) (8.32/9990 Germany.)

This new engine has been constructed by the Government Institute of Scientific Motor-car Research. It is a 5-cylinder radial, I $25 \mathrm{~mm}$. bore, I $40 \mathrm{~mm}$. stroke. It is rated at II h.p. at I600 r.p.m., and is known as the Nami-ioo. In a general design the engine resembles the German Siemens. The crankshaft and master connecting rod are mounted on ball bearings.

Air-Cooling in Aero Enqines. Experiments on Heat Control and Increase in Power Output in Air-Cooled Aero Engine Cylinders. (Dr. Ing. F. Gosslau, pp. I $33.5^{-1} 340$, Zeitschrift des V.D.I., September 22nd, 1928. No. 38.) (8.32/i0005 Germany.)

The air-cooled cylinder under test is heated by means of an internal oil bath, and its temperature measured by means of thermo couples in air streams of various velocities for various cylinder shapes. From the results the author is able to predict the changes in temperature resulting from a change of scale. A limiting temperature of $300^{\circ} \mathrm{C}$, is taken, and the maximum power obtainable per cylinder with the materials in present use is about 70 h.p. By supercharging it should be possible to reach too h.p. per cylinder. The stroke might be increased with advantage rather than the bore.

Evaporative Cooling. (Alfred H. Marshall, Hartford, Conn., Mechanical Engineering, September, I928, p. 695.) (8.34/9988 U.S.A.)

Comparative experiments between water-cooling and steam-cooling on a Chevrolet truck engine gave equal performances from i,000-2,000 r.p.m. The steam-cooling gave considerably less dilution of the oil in the crankcase, but incurred loss of steam and water on stopping quickly after a run. This can be avoided by running the engine light for some minutes before switching off.

The Schliha Two-Stroke. (H. Baechler, Motorwagen, December 2oth, I928, p. 862.) (8.87x/9997 Germany.)

A hollow stepped piston has a tubular extension fitted to the compression space. Crankcase scavenging air is introduced into the combustion space through the hollow piston and extension. During the explosion stroke the step piston 
is cooled by fresh air drawn in. The first part of the scavenging charge consists almost entirely of air introduced near the head of the cylinder through annular ports in the stepped piston, whilst the exhaust port opens at the bottom, giving good scavenging and negligible waste of fuel. An engine of I94 cc. stroke volume develops nearly 9 h.p. at 4,500 r.p.m.

\section{Engine Accessories, Instruments, Etc.}

New Anti-Freezing Compound for Water-Cooled Engines. (Motorwagen, September 30 th, I928, p. б5 I.) (8.37/10000 Germany.)

The I.G. Farbenindustrie has put on the market a new anti-freezing compound "glysantin," a derivative of ethylene glycol, of density I. I I at I $5^{\circ} \mathrm{C}$., b.p. $188^{\circ} \mathrm{C}$., m.p. at $-19^{\circ} \mathrm{C}$. An aequeous solution containing 30 per cent. glysantin shows separation of ice crystals at $-16^{\circ} \mathrm{C}$. and becomes opaque at $-2 \mathrm{I}^{\circ} \mathrm{C}$. The increase in volume on freezing is 0.8 per cent., compared with that of water 9 per cent. The viscosity is practically that of water. "Glysantin" is not lost by evaporation and has no corrosive action.

Junkers' L.55. (Z.F.M., September 14th, 1928, p. 386.) (8.62/9992 Germany.) A centrifugal compressor is driven at a variable speed by hydraulic gear, the slip-in gear and the speed of the compressor being adjusted automatically by the atmospheric pressure. For a dry weight of $650 \mathrm{kgms}$. the engine develops 525 h.p. at i 5,000 feet, with supercharger and 700 h.p. on the ground with slight ground boost.

Aeroplane Engine Starter. (Automotive Industries, November $3^{\text {rd, }}$ 1928, p. 635.) (8.82/9994 U.S.A.)

A new inertia starter (Type C) has been developed by the Aero-Marine Starter Co,, Keyport, N.J. The universal joint in the hand-crankshaft has a large angular adjustment, which permits cranking from either side of the fuselage or in the cockpit to give one-man starting. The mechanism weighs $17 \mathrm{lbs}$, and will start engines up to 300 h.p.

The New Type of Flying Machine. (Mr. Chappedelaine's Gyropter, L'Aerophile, I 5 th July, I928, p. 21 I.) (8.86/rooro France.)

The Gyropter relies both for sustentation and propulsion on air jets supplied from two turbines, which are driven by means of a petrol engine placed inside the aircraft. No wings are fitted. A model to $\mathrm{I} /$ Ioth scale is stated to have flown successfully, and to have shown a lift corresponding to io lbs. per h.p. The aircraft is intended to be mancuvred entirely by giving suitable direction to the issuing air stream.

The Effect of Hydrocarbon Vapour on the Contact Points of Ignition Apparatus.

(E. A. Watson, Automobile Engineer, September, 1928, p. 347.)

(8.91/9995 England.)

It is sometimes found that the contact points of the ignition fail after a short period of service. There is evidence that failure is due to a deposit of extremely finely divided carbon from the decomposition of hydro-carbon vapours by electrical discharge. Proper ventilation of the magneto eliminates the trouble.

Air Filter for Aircraft Engines. (L'Aerophile, ${ }^{1} 5^{\text {th }}$ July, I928, p. I9.) (8.542/9914 France.)

Fine wire gauze, pleated into a series of strips of varying dimensions and placed in the in-take funnel of the carburettor, forms an effective filter without obstructing the flow of the air, and acts as a flame stop in the case of backfire. The weight for a 450 h.p. engine amounts to approximately ro lbs. 
The Measurement of Maximum Cylinder Pressures. (Chester W. Hicks, N.A.C. for A., Report No. 294.) (8.632/9957 U.S.A.).

This investigation mainly brings out the limitations of the available instruments. The main factors are the friction and inertia of moving parts, the differential areas exposed in balanced-gas indicators, and the short duration of the maximum cylinder pressures.

So far the greatest accuracy in determining maximum cylinder pressures can be obtained with an electric, balanced-pressure diaphragm or disc-type indicator with a diaphragm or disc or relatively large area and minimum seat width and mass.

\section{Aerodynamics and Hydrodynamics}

\section{Hydrodynamics, Experimental}

Fluid. Resistance to Moving Spheres. (R. G. Lunnon, Roy. Soc. Proc. I.I8, pp. 680-694, April 2nd, 1928.) (5.32/10023 England.)

Experimental determinations of the time of fall in water of spheres of steel, bronze and lead up to $5 \mathrm{~cm}$. in diameter for distances up to $200 \mathrm{~cm}$, give a resistance coefficient, which is plotted against the Reynolds number, and the experimental points for all three materials are found to lie on a single smooth curve in good agreement with Wieselberger's results. A descriptive account of the fluid motion round a falling sphere is given.

Velocity in the Boundary Layer of an Immersed plate. (M. Hansen, Report of the Aachen Aero. inst., Z.A.M.M., Vol. VIII., Part 3, June, 1928, pp. 185-199.) (5.32/10024 Germany.)

After reference to the solutions of Prandt1, Blasius and V. Karman for laminar and turbulent flow and the experiments of Burgers and V.D. Hegge Zynen, a description is given of the scope and object of further experimental work. Seven types of leading edge are specified, more or less sharp or rounded, and of various materials. Types of surface are specified as smooth, undulating, rough and very rough. The numerous experimental results are exhibited graphically in 25 diagrams, and comparisons are made with the results of other workers. It may be taken that they confirm substantially the accuracy of the formula: given by Blasius and V. Karman

Experiments on the Fall of Spheres and Discs in Viseous Fluids. (J. Schmiedel, Phys. Zeit., No. 17, 1/9/28, pp. 593-610.) (5.32/10025 Germany.)

The resistance of spheres falling uniformly along the axis of a cylinder containing a viscous fluid is determined experimentally for small Reynolds numbers and compared with the formulæ of Stokes, and with the modifications by Oseen, H. A. Lorentz and H. Faxen.

The influence of two plane walls was worked out by $R$. Ladenburg, and is used to reduce the effects of the cylinder walls. The calculated and experimental results are tabulated in non-dimensional form and compared after reduction with the case of an infinite medium. At the higher speeds the agreement is within a few per cent.

In the fall of circular discs, oscillations appeared from $R=80$ upwards, about a quite arbitrary equatorial axis, and were coupled with a spiral path of descent. A coloured fluid indicator exhibited the formation of periodic eddies at opposite ends of the transverse diameter alternatively analogous to those formed in two dimensions at opposite sides alternately by the fall of an elongated rectangular plate. 
The mean rates of fall and mean coefficients of resistance are tabulated in Table VII. and the coefficient of resistance shown graphically in Fig. 5 on logarithmic scales against Reynolds number.

On the same type of scale the non-dimensional quantity $N d / v$ lies on straight lines for different constant ratios of density of body to density of medium. This quantity is analogous to the ratio $h / l$ in the theory of V. Karman's street eddies, which gives a resistance varying as the square of the velocity. Actually $N d / v \cdot<h / l$.

The whole of the experimental work was carried out in an elaborate manner. Photographs show spheres and discs detaching periodic eddies.

\section{Hydrodynamics, Mathematical}

Integration of the Equations of Flow with Axial Symmetry in Pipes. (Sexel, Ann. d. Phys., Vol. LXXXVII., Part 4, No. 20, pp. 570-580.) (5.32/10028 Germany.)

The mathematical methods of classical hydrodynamics are unsuitable for turbulent flow, which requires statistical methods. Laminar flow between parallel plates is mathematically analogous to laminar (Poiseuille) flow in straight pipes of circular section, and both are stable for symmetrical disturbances. (ABstractor's NotE.-This mathematical result is in contradiction with a physical point of view.) Neglecting the terms of the second order, interesting integrals are obtained in Bessel functions which are interpreted as the aperiodic subsidence of axially symmetrical disturbances. No progress has been achieved with the second order terms.

The Resistance of a Disc Rotating in a Fluid. (C. Schmieden, Z.A.M.M., Vol. VIII., Part 6, December, 1928, pp. 460-479.) (5.32/10030 Germany.)

The general differential equations of viscous fluid motion are written down in vector notation and transformed to polar co-ordinates. For assumed steady motion solutions are obtained involving Bessel functions satisfying icertain boundary conditions. The numerical solution depends on an integral equation and a scheme of numerical reduction and computation is given.

Hydrodynamical Applications of Elliptical Functions. (W. Muller, Z.A.M.M., Vol. VIII., Part 6, December, I928, pp. 447-45I.) (5.32/1003I Germany.)

Elliptical functions of a complex variable have a real and an imaginary part which may be interpreted as velocity components of a field. Several examples are given of functions involving $C n Z, s n Z, d \boldsymbol{m} \%$, and graphical illustrations are added.

Stability of the Karman Vortex Row, under Arbitrary Disturbances in Three Dimensions. (K. Schlayer, Z.A.M.M., Vol. VIII., Part 5, October, I928, pp. 352-372.) (5.32/10032 Germany.)

Von Karman limited his investigation to two-dimensional disturbances. The author introduces three-dimensional disturbances, forms a new differential equation for stability under more general conditions and obtains an equation of the sixth order as criterion of stability.

In interpreting the conditions physically the author states that slight curvature of an individual vortex filament does not destroy the equilibrium unless resonance occurs between the self-induced velocity and the mutual induced velocity of the other vortices.

Should the curvature become too great an individual vortex may become unstable with reference to the influence of the neighbouring vortices. Approxi- 
mate criteria are found which suffice for most types of disturbances by breaking: up the general criterion into factors by neglecting relatively small terms, a method: familiar in the problems of aeroplane stability.

Equation of Viscons Motion and the Circulation Theorem. (H. Jeffreys, Proc. Camb. Phil. Soc., Vol. XXIV., Part 4, October, I928, pp. 477-479.) $\left(5 \cdot 3^{2} / 10033\right.$ England.)

On Stokes' assumption that the relation between rate of strain and viscous stress is linear, the general equations are derived briefly and compactly by the use of tensor notation.

The expression for the rate of change, in time, of the circulation round a. closed fluid line is obtained in the same notation, as an integral, with five terms. in the integrand. The pressure term vanishes if $p$ is a function of $\rho$ only, but not otherwise, a fact which may be important in meteorology. The second and fifth terms involve products of viscosity by divergence and are taken to be of small influence in most cases. The fourth term shows that variable viscosity may produce circulation internally. The third term is the only one left for an incompressible fluid and its form shows that the vortices shed by an aeroplane starting up have initially circulation round them equal and opposite to that round: the aerofoil.

The Vector Integrator for the Mechanical Solution of Potential and Vortex Problems. (H. Fottinger, Zeitschr. f. Tech. Physik, 9, p.p. 26-39, 1928. Abstracted in Zeitschrift fur Instrumentenkunde, II/II/I928, p. 564.) $(5 \cdot 32 /$ roo4I Germany.)

An instrument is described for solving equations in products of Bessel functions of different kinds, and products of Bessel functions and elementary transcendental functions. It is stated that the instrument saves a large amount of labour and time in the solution of hydrodynamic equations.

\section{Aerodynamics, Experimental}

Wing Characteristics through a Large Range of Incidence. (C. J. Wenzieger and T. A. Harris, Coll. Memorial Aeronautical Jaboratory, N.A.C.A. Technical Note, No, 294.) (5.31/1002 I U.S.A.)

A number of profiles are tested from about $-45^{\circ}$ to $+9 \mathrm{c}^{\circ}$ as monoplanewings, biplane wings with varying stagger and difference of incidence, and with varying plan form, and with variable flap incidence. The results are given as, $C_{1} / C_{\mathrm{d}}$ curves in 18 diagrams. The application is to abnormal flight attitudes in aerobatics.

Drag and Cooling with Various Forms of Cowling for a "Whirlwind" Engine in a Cabin Fuselage. (F. E. Weick, Technical Notes National Advisory Committee for Aeronautics, No. 301, November, I928.) (5.322/10017 U.S.A.)

A conference of aircraft manufacturers at Langley Field, May 24th, 1927, put forward the problem of cowling and cooling air-cooled engines (radial) as suitable for investigation in the new $20 \mathrm{ft}$. airscrew research channel.

This channel is of open throat type, diameter $20 \mathrm{ft}$., maximum velocity i 10 m.p.h. (N.A.C.A. Tech. Report, No. 300, i928. D. H. Wood). The programme adopted included ten main forms of cowling to be tested on a J-5 engine mounted successively on two fuselages, three cowlings on an open cockpit fuselage and seven on a closed cabin type. 
The tests on the three open fuselage cowlings, numbered I, 2 and 3 havenot yet been carried out. The seven tests on the covered cabin fuselage are tabulated as follows.-

No. 4. No cowling over cylinders or crankcase. Tested with and without wing (Fig. I).

No. 5. Cowling covering slightly less than one-half of each cylinder and over crankcase. Tested with and without wing (Fig. 2).

No. 6. Same as No. 5 but with spinner. Tested with and without wing. (Fig. 3).

No. 7. Cowling over nearly all of each cylinder and over crankcase (Fig. 4).

No. 8. Same as No. 7 but with spinner (Fig- 5).

No. 9. Single cowling completely covering cylinders, but no cowling over crankcase (Fig. 6).

No. 1o. Same as No. 9, but with internal cowling similar to No. 5 over lower portion of cylinders and crankcase (Fig. 7).

In experiment No. 4 there is no cowling, in Nos. 5-Io the diameter of the cowling increases regularly, leaving less and less of the cylinder heads exposed. until in cowlings 9 and 10 the cylinder heads are totally enclosed.

Fig. 30 shows graphically the relative drags of the cowlings Nas. 4-Io with: fuselage onely, Nos. 4-6 with fuselage wings, No. ro with cooling modification. and for comparison the bare fuselage with rounded nose.

The curves take the forms of nearly straight lines from 50 to I Io m.p.h.

Taking the drag of $25 \mathrm{lbs}$. weight at $85 \mathrm{~m}$.p.h. on the bare fuselage with. rounded nose as the unit of comparison we get the following figures :-

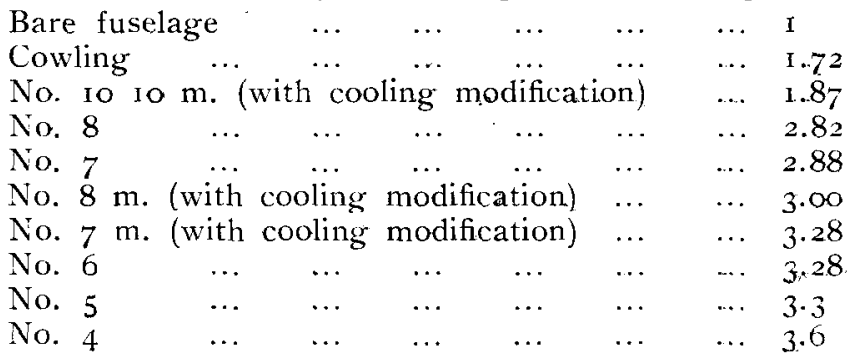

Diagrams 32 and 33 show airscrew efficiencies. Again No. Io shows the best results with a slightly higher maximum efficiency (0.79) and a slightly wider range of high efficiency, but the differences are much less marked.

Full-scale flight tests of No. Io cowling were made on a Curtiss AT-5A aeroplane at low altitude with full power. On the original machine a maximum speed of II 8 m.p.h. was obtained at I,900 r.p.m. With the new cowling a speed of 118 m.p.h. was obtained at I,720 r.p.m. and a maximum speed of 137 : m.p.h, at $I, 900$ r.p.m.

The cooling of the engine was normal and there was no interference with the pilot's view. The controllability was also improved and rendered smoother by the improved flow of air round the fuselage.

Inverted Flight. (A. Williams, Lt., U.S.N., Aero Digest, September, 1928, p. 423.) (5.322/10020 U.S.A.)

The author is a well-known expert in aerobatics. The N.A.C.A. supplied and installed a three component accelerometer mounted at the c.g., a recordingair speed meter and an altimeter. (ABstracton's Note.-The readings of the air speed meter obviously require cautious interpretation in any but straight 
flying.) The manœuvres carried out are described as inverted flight, inverted turn, inverted tail spin, inverted loop, outside loop, vertical figure S, and "other experimental manouvres."

The value of studying control movements with a model is emphasised. The importance of absolute confidence in the efficacy of the safety belt is mentioned on account of its influence on the pilot's freedom to concentrate on instruments and controls. Numerous practical points are discussed with exemplary clearness.

Two diagrams give simultaneous readings of three acceleration components, altitude and air speed reading. In an outside loop $-3 \mathrm{~g}$. is recorded. A complete roll about the rolling axis is described and a diagram of readings is given. Applications to fighting in the air are suggested and discussed.

Experimental Investigation of Wing Profiles arranged in Echelon (Cascade).

(K. Christiani, Göttingen, Report of the Aerodynamical Laboratory of the

Kaiser Wilhelm-Gesellschaft, L.F.F., Vol. II., Part 4, 27/8/28, pp. 9I-I Io.)

(5.42/10022 Germany.)

The object of the investigation is to derive data for airscrew design. The practical method followed is entirely similar to that used in this country. An interesting theoretical discussion of the mutual effects of the wings is given in accordance with the principles of the Prandtl-Lanchester theory, for a perfect fluid.

Semi-empirical methods are applied to take account of the retarded wake and of the retarded air along the walls of the wind channel. A number of pressure distribution curves are given, and polar curves for different conditions. Plots are given of the energy loss in the wake and the general results are published in 19 numerical tables. The conclusions are naturally somewhat involved, and follow the lines of results obtained in this country.

\section{Aerodynamics, Mathematical}

Theories of Flow Similitude. (A. F. Zahm, National Advisory Committee for Aeronautics, Report No. 287.) (5.32/10026 U.S.A.)

The laws of comparison of dynamically similar fluid motions are derived by three different methods initiated respectively by Newton, Stokes (or Helmholtz), and Rayleigh, viz., the integral, the differential, and the dimensional. A scheme is proposed for collating the results yielded by the three methods.

Streamline Motion of a Fluid in a Curved Pipe (Second Paper). (W. R. Dean, Phil., May 5, pp. 673-695, April, 1928, Science Abstracts, Section A, $25^{\text {th }}$ July, I928, pp. 523.) (5.32/10027 England.)

A first approximation to the solution of the equations of steady flow of an incompressible viscous fluid through a pipe of circular cross-section, coiled into a circle, failed to show that the relation between flow and pressure gradient depends upon the curvature. The analysis of the present paper represents a fourth approximation. From the results, the apparent increase of viscosity with flux, found by Grindley and Gibson, is shown to be due to the curvature, and begins to be appreciable at the expected value of the Reynolds' number. There is also good agreement with the experiments of Eustice, whose observation that there is no marked critical velocity for flow in curved pipes is also explained by the fact that lateral movement is present in a curved pipe at small speeds of flow, so that there is no marked change in the general configuration of mean flow when turbulence sets in. 
Interfercnce of Walls of Rectangular Wind Tinnels with Wing Characteristics.

(K. Terazawa, Report of Aeronautical Research Institute, Tokyo, No. 44" October, 1928 (Vol. IV., 3), pp. 69-81.) (5.32/10029.)

After reference to Prandtl's classical paper the author examines Glauert. extension of the method to rectangular channels. The ratio of the span of the wing to the distance between images is neglected by Glauert, and is brought in by the author.

Complete expressions are found in Weierstrass's integrals and transformed to theta-functions and finally expressed in Jacobi's q-series for computation.

Numerical examples are worked out for a model aerofoil of R.A.F. 16 section, 6-1 aspect ratio and 6 in. chord, tested in various tunnels.

For $4 \mathrm{ft}$. sq. tunnel and $7 \mathrm{ft}$. sq. tunnel the following figures are given :-

4 feet square.

Glauert. Terazawa.

$$
\Delta a_{0} / c_{\mathrm{a}}=0.74
$$$$
\Delta c_{\mathrm{w}} / c_{\mathrm{a}}{ }^{2}=0.013
$$

0.92

0.016
7 feet square.

Glauert. Terazawa.

$0.24 \quad 0.25$

$0.0042 \quad 0.0044$

The author concludes with a warning that the physical conditions are by now means those of a perfect fluid, and that further corrections may be required.

Meridian Plan of Airship Hulls. (A. V. Paricval, Z.F.M., Vol. XIX., Part 2r, November, 1928, pp. 493-495.) (I 2.33/100c8 Germany.)

A method is given of expressing the meridian plan form by means of an algebraic equation and of meeting various specified conditions as to volume, degree of taper towards the tail, etc. by varying the parameters. There appears. to be no physical basis for the equations.

\section{Aerodynamics, Full Scale Tests, Wing Flutter, Windmills, Etc.}

Flying Tests and Wind Channel Measurements on the "Udet" Light Aeroplanes, “U.6,", “U.7," "Kolibri," "U.r2,", "Flamingo." (H. Herrmann, Z.F.M., Vol. XX., Part I, 14/1/29, pp. 3-15.) (5.322/3/9907 (Germany.)

A historical note of the development of light aeroplanes in Germany is given, and is followed by test records of the types mentioned, particularly for spinning. Fig. 6 gives the polar curves of U.6, Fig. 7 of U.7, Fig. 8 of U.r2, all showing a marked increase of resistance at an elevator angle of $20^{\circ}$ and a discontinuity of the moment curve at high incidence, Figs. 9, 10 and $I$ I show the change of the polars in a side wind, the resistance being greater in every, case. Figs. 12 and 13 show the effect of simultaneous side rudder and elevator.

Spinning is investigated, and the characteristic cross velocities for different incidence and rudder settings are exhibited in a series of curves at different relocities. The longitudinal moment and the inertia forces are discussed, and the aerodynamic and inertia moments are compared in diagrams. It is noted that the U.6 once went into a spin and failed to come out; a reference is made: to English work on the falling off of the longitudinal moments at high incidence, but it is not understood why the longitudinal moment of the U.6 fell off to such an extent, and further wind channel tests are required.

Experimental Determination of the Polar of an Aeroplane and of a Bird in Flight. (Huguenard, Magnan and Sainte Lague, pp. 559-56r, Comptes Rendus, No. 14, October Ist, I928.) (5.322/1001 I France.)

Using a cinema gun camera the trajectory of an aeroplane during a gliding flight can be followed and its resistance coefficients determined, the airscrew turning at the speed of zero slip stream. The fineness ratio of a complete fast: 
aeroplane under these conditions is of the order of 6 . Assuming an airscrew efficiency of 80 per cent., an engine of 180 h.p. should develop a speed of $25^{\circ}$ k.m. an hour. Actually this h.p. only gives an air speed of $200 \mathrm{k} . \mathrm{m}$. an hour. The discrepancy is a measure of airscrew interference. From experiments on the gliding flight of a swallow the fineness ratio was estimated at 19.5 , over three times that of the fast aeroplane.

The Effect of Tip Shields on a Horizontal Tail Surface. (Paul V. Dronin and Earl I. Ramsden, the Danie! Guggenheim School of Aeronautics, New York University, and George J. Higgins, Langley Memorial Aeronautical Laboratory, Technical Notes, National Advisory Committee for Aeronautics, No. 295.) (5.335/10018 U.S.A.)

Some aerodynamic gain can be obtained by the use of tip shields on horizontal tail surfaces, though it is considered doubtful whether their use would be practical in view of the increased weight and of the structural difficulties.

Windmills in the Light of Modern Research. (A. Betz, from Die Naturwissenschaften, Vol. XV., No. 46, November 18th, 1927, Technical Memorandum, National Advisory Committee for Aeronautics, No. 474.) (5.38/10036 Germany.)

An expression is obtained for the maximum work obtainable from a windmill with a given sail diameter operating in a wind of a given speed. The efficiency of the mill is defined as the ratio of the maximum work obtainable in practice to this ideal limit. Experiments show that under the most favourable condition between $5^{\circ}$ and 60 per cent. of the ideal limit can be reached. The primary consideration, in windmill design being that of first cost there is not much scope for modification of commercial designs.

Aleron and Wing Vibrations. (Thoret, L'Aerophile, November, 1928, No. $2 \mathrm{I} / 22$, p. 333.) (5.21 I/roorg France.)

On a French light aeroplane considerable wing and aileron vibrations were "noted when flying at high speed in "bumpy" air. By throttling down and a short glide, the vibration could be damped out. The vibrations were traced to slackness at the aileron hinge.

\section{AIRCRAFT DEsign AND EQUiPMENT}

\section{General Design}

The Coming Development of Giant Aeroplanes. (B. v. Romer, Luftfahrt, 22/10/27, pp. 307-311, Trans. Tech. Mem. 463, N.A.C.A.) (5.14/9909 Germany.)

The paper consists of an account of projected giant aeroplanes-Junkers "G.3I, three Jupiter engines, I,350 h.p., 25 passengers, the Rochbach "Rocco "; the Dornier "Super-wal," two Rolls-Royce engines, I, 300 h.p., actually in existence, will be followed by the Dornier "R-Jas" with four Jupiter engines, I, 800 h.p.

The "J-Iooo" of Professor Junker approaches the ideal of enclosing all working parts within the wings. It is of Canard type, with four $3,000 \mathrm{~h} . \mathrm{p}$. angines.

Junker likewise projects a still larger monoplane with six hulls and ten I, $\infty$ h.p. engines in pairs between the hulls.

Klamt projects a seaplane with five 3,000 h.p. engines.

Abstractor's Note.--These designs seem more or less fantastic. 
Structures of Thin Sheet Metal. (H. Wagner; Technical Memorandum, No. 490 , N.A.C.A., translation of an unpublished paper received in advance from the author.) (5.11/9910 Germany.)

On the assumption, by no means established, that light metal construction has advantages which outweigh the disadvantages, various types of sheet metal construction are investigated, and surprise is expressed at the great variety of views as to the correct analysis of stresses, applied to and supported by the metal.

Generally speaking, designers seek to employ the metal to the best advantage by applying it to the cover of the wing in such a way that the strain energy is fairly uniform during flight. There are longitudinal stresses introduced by. bending and shearing stresses due to torsion. To prevent local buckling, stiffeners must be attached at distances not exceeding 60 times the thickness. For thin steel sheets of $.25 \mathrm{~mm}$. thickness the spacing is only $15 \mathrm{~mm}$. For duralumin the dimensions are about 3 times as great.

Junker employs corrugations running in the direction of air flow which increase the stiffness to torsion but not to bending.

Dornier uses the metal skin chiefly as a covering, and torsional moments are absorbed by internal wing strut bracing as far as possible.

Reference is also made to Breguet's duralumin bodies.

Wing Structure of Giant Aeroplanes. (E. Offermann, translated from "Riesenflugzeuge," I 927 (Giant Aeroplanes) for N.A.C.A., Technical Memorandum No. 478.) (5.14/10007 Germany.)

In Chapter III., Section B, the effect of increase of size on aeroplane characteristics is discussed, and a tabular comparison is given between Lanchester's results and Rohrbach's results.

Lanchester confines himself to geometrically similar aeroplanes with an. assumed constant flight speed, landing speed and load factor, the method is therefore incomplete but suffices to indicate the main points, namely, that the percentage useful load falls off with size and the actual useful load increases: to a maximum and then falls off, becoming negative beyond about 17 tons, but. the power per kilogram and per $\mathrm{m}^{2}$ remains constant, as also the kilograms. per sq. metre, wing loading.

Rohrbach increases the wing loading from $40 \mathrm{~kg} / \mathrm{m}^{2}$ at 2 tons total weight. to a $100 \mathrm{~kg} / \mathrm{m}^{2}$ at 32 tons total weight. The landing speed increases from. $80 \mathrm{~km} / \mathrm{hr}$ to $127 \mathrm{~km} / \mathrm{hr}$, the flying speed from $1 \mathrm{I} 7 \mathrm{~km} / \mathrm{hr}$ to $270 \mathrm{~km} / \mathrm{hr}$. The $\mathrm{hp} / \mathrm{m}^{2}$ increased from 5 h.p. to 20 h.p. As before, the percentage useful load falls with size from the beginning, the total useful load increases to 2 . I tons for a total of 16 tons, then falls off and becomes negative.

Abstractor's Note.-Neither method brings out with sufficient clearness. that to obtain the increase of size the "performance" is affected adversely in a number of ways, which may, however, be permissible in designing a large machine for some special purpose.

\section{German Long Distance Record. (V.D.I., Part 29, July 2 Ist, I928, page Io32.) (4. I 4/roor 2 Germany.)}

The new world's endurance record of 65 hours 25 minutes was obtained on a Commercial aeroplane type W.33 with an L.5 Junkers engine of 300 h.p. normal rating fitted with a metal airscrew il $\mathrm{ft}$. diameter. The aeroplane weighed empty $1,362 \mathrm{kgs}$. This includes water in the radiator, as well as oil in the crankcase. It was loaded with $2,385 \mathrm{kgs}$. benzol, $75 \mathrm{kgs}$. lubricating oil, $13.2 \mathrm{kgs}$. instruments, $15 \mathrm{kgs}$. food and $150 \mathrm{kgs}$. for the two pilots. The 
total load is thus just over 4 ,, $00 \mathrm{kgs}$, mean fuel consumption $35.6 \mathrm{kgs}$. per hour, total oil consumption for the 65 hours $17 \mathrm{kgs}$, an exceptionally low figure. The compression ratio of the engine was 7 to $\mathrm{I}$. Under better weather conditions another five hours might have been achieved.

The Mechanism of Long Distance Flight. (L. Steiner, Zeitschrift fur Flugtechnik und Motorluftschiffahrt, 28th December, 1927, p. 567, translated for A.R.C.) (4.14/10013 Germany.)

The importance of engine fuel economy under varying conditions of load and speed requires closer attention, especially by provision of instruments for the maintenance of the most economical flying conditions.

Cinematograph Measurement of the Motion of an Albatros L.68 in a Spin. (W. Hubner and W. Pleines, Io6th Report of D.V.L.) (5.322/9906 Germany.)

A description is given of the cinmatograph apparatus used, with 2 photographs, and details of the reduction methods employed. A photograph of the machine used is also given.

The correction for wind velocity is given at some length and the various quantities observed and are tabulated in Tables $I$ and 2 , at intervals of $I / 1$ oth second (with a few exceptions). The reduced points are considerably scattered about a smooth mean curve, but the accuracy is considered to be equal to that iof other methods employed in determining the component velocities. The axis of the spin is found to be about 4 metres forward of the leading edge of the upper wing. The mean angular velocity found is 2.55 radians per sec. The horizontal component of the centre of gravity is I 2 m.p.s., the vertical component 30 m.p.s., the path velocity 32.5 m.p.s. These are all mean values.

A coefficient of spinning is defined as the ratio, span $x$ angular velocity / 2 path velocity, the value varying from 0.34 to $0.4 \mathrm{I}$.

The incidence at mid-wing was about $38^{\circ}$, at the outer tip $17^{\circ}$, at the inner tip $59^{\circ}$.

\section{Structures}

Strength of Bolts Piercing Wooden Members. (M. Schrenk and M. v. Pilgrim, I I 4th Report of the D.V.L., L.F.F., Vol. II., Part 5, I5/12/28, pp. I47I6o.) (5.2/9908 Germany.)

A systematic series of tests is laid out in which bolts of varying diameter ibut of constant ratio length/diameter, passing through varying thicknesses of selected and graded timber, are loaded up to the point of collapse. The mechanical arrangements are illustrated by photographs and diagrams, and the experimental results are collected in tables and graphs. Fig, 18 gives a diagrammatic summary of the results expressed as percentages of the average crushing load of $46_{5}$ kilograms per $\mathrm{cm}^{2}$.

The tests are divided into two classes according as the bolts retained their shape more or less or were much bent under load. Bolt piercing the wood at right angles to the annual rings gave ${ }_{5} 5$ per cent. higher resistance than bolts tangential to the rings. A bibliography of sixteen entries is added.

Wing Span as Fundamental Factor in Aeroplane Design. (G. Lachmann, Z.F.M., May I4th, 1928, pp. I98-208, translated for N,A.C.A., Technical Memorandum No. 479.) (5.21/10016 Germany.)

The aerodynamical need for a relatively large aspect ratio, and the structural disadvantages of a large span, bring into prominence this factor in design. In 
particular the paper deals with its effect in increasing the angular inertia of an aeroplane and thereby decreasing its manœuvrability for aerobatics in sport and in war.

Structural Weight of Aircraft. (Crocco, G. A. Atti del Accad., Lincei, No. 7 , I9th February, I928, pp. 273-278.) (5.26/10014 Italy.)

The minimum weight of an ideal structure is proportional to the forces at the joints and to the distance between joints. Applying parallel forces in equilibrium, and torsion couples in turn, stress weight relations are obtained for the two cases, appropriate coefficients being assumed for the strength of the material employed. This leads to a calculated limit for aeroplane structures.

Strength Calculations and Static Tests in Russia. (Article translated from L'Aeronautique, February, 1928, pp. 42-45, for N.A.C.A Technical Memorandum No. 480.) (5.26/10015 Russia.)

The writer makes a comparison between the methods of specification and stressing laid down by the Directorate of the Soviet Air Forces in 1927 with the French methods. These are obviously adapted from methods current in other countries, but indicate the existence of a technical design section equipped for dealing with such matters.

\section{Airscrews}

Contribution to the Theory of Screw Propellers. (G. Madelung, L.F.F., Vol. II., Part 5, I5/12/28, pp. I I I-1 46.) (5.4ז/9964 Germany.)

This comprehensive paper is a short treatise on the design of airscrews anticipated by the paper of Karman and Bienen, but developed in a manner more convenient for the design room. The different conditions of operation are laid down and their effect on the performance, particularly efficiency, is studied. The first figure gives curves of equal efficiency, the coordinates being pitch of motion and r.p.m. on logarithmic scales. The highest efficiency shown, 0.80 , lies on an oval curve, one of a family, with the maximum (at a conjugate point) of about. 0.85 .

The influence of the disc area is exhibited in three sets of curves, the coordinates being disc area and efliciency. A further set of three curves gives the relation between efficiency and r.p.m.

The problem of the best r.p.m. is discussed and a graphical solution is obtained, from a family of curves, of a quantity $k_{\mathrm{d}}$ which is defined as the total torque power divided by the torque power of a geometrically similar airscrew of unit disc area, unit angular velocity, and of an artificial density half that of standard atmosphere. The figure shows that the best angular speed varies with extreme slowness save for exceptionally high loadings.

The best forward speed is discussed and exhibited graphically as a function of disc area and efficiency. A comparison is given between Bendemann's theoretical results and results obtained in practice as a function of $k_{\mathrm{d}}$ and efficiency, the maxima being 0.98 and 0.85 respectively.

For the purposes of calculation, a large number of graphical figures are given permitting the designer to read off the numerical values of power, efficiency and r.p.m. for given conditions of operation.

The Effect of the Body on Airscrew Design. (Troller Th., Report of Aachen Aerodynamical Institute, Z.F.M., Vol. XIX., No. I 4, 28/7/28, pp. $3^{25}$ 328.) (5.4.1/9965 Germany.)

The work of Bienen, v. Karman and Helmboldt on airscrew design is taken as the basis of an important extension to the interference between body and screw. (Bienen and v. Karman, Z.V.D.I., I924; Helmboldt, Z.F.M., 1924.) 
In No. 6 of the reports of the Aachen Aerodynamical Institute, v. Karman gives expressions for the velocity potential of steady flow past an airship hull obtained by building up a distribution of sources and sinks along the axis. The method is applied here to find the effect of the body, which is taken as a surface of rotation in the airscrew stream.

Four arbitrary points on the body are chosen and four distributions of double sources along sections of the axis are assumed. The resulting four linear equations in the four unknown intensities of distribution are readily solved. The deflection of the streamlines and the corresponding changes in the momentum imparted to annular elements are plotted as functions of the radius.

The effect on the efficiency is found to be small-a reduction from 0.89 to o.88. The fluid is assumed to be inviscid so that the problem is of an ideal nature, but there is no reason to doubt that the result gives a useful indication of the order of the effect at the airscrew disc.

The increase of drag on the body is thus not dealt with, but it is presumably increased in something like the ratio of the square of the resultant speed, with probably a much larger adverse effect than that on the airscrew directly.

Circulation Theory of the Screw Propeller. (Einar Hogner, Upsala Liniversity and Hamburg Schiffbauversuchsanstalt, Ann. d. Phys., Vol. LXXXVII., Part 3, No. 19, I928, pp. 385-423.) (5.41/9966 Germany.)

The problem of the induced velocity field round an airscrew with a small number of blades was not oompleted by Betz and Prandtl. The present author writes down integrals expressing the three components of the induced velocity field due to a spiral vortex filament, in the usual manner.

Inserting the values of the induced velocity components he writes down the thrust, torque and effective loss as the integrals, taken over the blade, of the products of circulation and velocity components, and inserting the values of the latter obtains general expressions as the sum of a single and a double integral over the blade. The resultant thrust for a small number of blades follows at once by superposition.

The problem of obtaining minimum effective loss is then attacked; the " frictional" losses are neglected. The " minimum" loss thus found is approximate, but it is claimed that the approximation is sufficient for selection of the best design.

Applications of Joukousky's Vortex Theory of Airscrews. (W. Margoulis, La Technique, Vol. XIX., No. 85, November, 1928, pp. 174-185:) (5.41/9967 Russia.)

In anticipation of the publication of a new book by Jowkowsky on airscrews in a French trnslation, the author gives a summary of the principles. Expressions are written down for apparent and effective relative velocities, circulation, incidence, etc. The various relations occurring in design are reduced to a set of five abacs or nomographs from which numerical values may be read off for any prescribed conditions.

The Influence of Variable Inflow on the Screw Propeller. (E. Petersohn, Göttingen, Report of the Kaiser Wilhelm Institut fur Stromungsforschung, Werft Feederei Hafen, Part Io, Vol. VIII., 1928.) (5.41/10034 Germany.)

The airscrew is assumed to work in a stream of variable velocity, increasing vertically across the disc. Corresponding corrections are made in the usual integral expressions for thrust and torque, and the effects are given graphically in eight diagrams. It is found from the numerical examples that there is an 
increase in the efficiency of the screw, but little effect on the selection of the best blade.

High Speed Railways with Airscrew Drive. (K. Wiesinger, Z.F.M., Parts I9 and 20,1928 , p. $45^{6}$.) (5.41/10035 Germany.)

It is proposed to drive trains by front or rear airscrews run on the normal track at speeds of the order of $160 \mathrm{~m} . \mathrm{p} . \mathrm{h}$.; the h.p. per passenger being only 20 per cent. greater than on normal trains at $40 \mathrm{~m} . \mathrm{p} . \mathrm{h}$., by careful streamlining and by reduction in weight.

Measurement of Engine Torque in Flight. (M. Poincare, L'Aerophile, I-I5, October, 1928, p. 309.) $(5.45,9062$ France.

A planetary reduction gear is readily adapted to measuring engine torque. The sun wheel is driven by the engine crankshaft, and the planet wheels drive the airscrews, the necessary reaction being produced by an internal tooth gear meshing with the planet wheels and mounted on the casing. The latter is mounted on ball bearings, and the engine torque is measured by the couple required to keep it stationary. Messrs. Farman have modified their conical epicyclic reduction gear on these lines, the gear wheel in question being held stationary by oil pressure which measures the torque. It is identical in general dimensions with a normal reduction gear, a great advantage over other torque meters which have been proposed.

The Measurement of Forces in Flight. (F. Seewald, Z.F.M., Parts I9 and 20, I928, p. 474.) (5.45/9938 Germany.)

A new form of thrust and torque meter is described, which is a development of the well-known instrument first used at Adlershof. The original attempt to combine both thrust and torque in one hub led to complications in design and has been abandoned. Two hubs are now provided, one for thrust and one for torque; for an analysis of airscrew performance consecutive flights one with each hub have to be made. Flights with zero thrust give the airscrew interference by use of a special sensitive recording gear. The acceleration of the machine as a whole measured by accelerometer is apt to be misleading, since the acceleration is not constant for the whole machine; it differs from part on account of the elastic deformation of the structure. The only satisfactory way is to measure the actual deformation in flight, and several extensometers are described, especially suitable for study of forces on sea-plane floats.

\section{INSTRUMENTS}

\section{Navigation and Instruments}

Method of Determining Position. (German patent No. 461970, Zeppelin Co., Flugsport, September I 2 th, r928, p. I I 4.) (6.3/9913 Germany.)

Certain substances, of nature unspecified, which can be identified in the airship, are sprayed into the atmosphere from the ground or from kite balloons or by gas shells.

A New Type of Densigraph. (Comptes Rendus, November I4th, I927, p. Ior6.) (6.9/9916 France.)

A constant tension spring acting on the shorter arm of an $L$ lever sets up a clock-wise couple. The longer arm is attached to an aneroid capsule. By making the shorter lever vary with temperature the effective couple can be made proportional to the temperature, whilst the restoring force varies inversely as the pressure and the rotation of the lever is a measure of the density of the atmosphere. 
On the Effect of Temperature Changes upon an Altimeter. (T. Sadaki, K. Hattori, I. Hagiwara and R. Tate, Report of the Aeronautical Research Institute, Tokyo Imperial University, No. 4I, September, I928, Vol. III.; ii:)' (6.33/9958 Japan.)

The temperature coefficient of an altimeter is large for other pressures than that for which it is compensated. If intended for accurate service, such as bombing or aerial photography, devices which compensate the temperature effect at all altitudes are required.

Drift Recorder. German patent No. 460966. (Prof. Junkers, Flugsport, September I 2 th, 1928, p. I I4.) (6.35/9912 Germany.)

An optical system forms a picture of the moving ground on a sheet of sensitized paper, the time of exposure being automatic. The paper is marked with a network, and from striation produced on the moving picture, the drift can be calculated.

Accelerometers. (Langer and Thome. Motorwagen, October 31st, 1928, p. 724.) (6.47/9936 Germany.)

A static form of accelerometer is described which records automatically the instant at which the acceleration exceeds a certain predetermined amount. A mass presses a spring against an electrical contact and breaks an electrical circuit when the acceleration exceeds the spring tension. The apparatus can be fitted into a small space and is being utilised to investigate the forces on landing carriages of aeroplanes when starting and stopping.

Float Coeffcients of Metering Nozzles Used for Water, Oil, Steam and Gas by the I.G. Firm of Ludwigshafen, Germany. (V.D.I., October 2oth, 1928, p. 1493.) (6.51/10006 Germany.)

The discharge coefficient was found to remain constant within $\pm \mathrm{I}$ per cent. for all the liquids tested, provided the flow took place at about a certain definite Reynolds' number. The principle of similarity is applicable to any one type of metering nozzle when using different fluids but not when changing the diameters of the tubes. The comparison between the metering nozzles developed by the I.G. and the standard nozzle of the V.D.I. shows substantial agreement. The I.G. nozzle, however, is to be preferred as being less sensitive to variation in manufacture.

A Modification of the Rayleigh Disc Method for Measuring Sound Intensities. (L. J. Sivian, Phil. Mag., Seventh Series, Vol. V., pp. 6I5-620, March, I928, reprinted by Bell Telephone Laboratories, Apri1, I928.) (6.79/99 I England.)

The usual procedure is to measure the steady deflection of the disc under the influence of a steady sound-field. Utilising the fact that the torque exerted on the disc is a non-linear function of the sound amplitude when the latter is a function of time, the amplitude of the sound-wave is varied with the frequency of the free vibration of the suspended disc and the amplitude of the corresponding oscillations of the disc is measured. The disturbances by air-currents are reduced, and in many cases there is a gain in absolute sensitivity.

Damping for Gyro-Compasses. (O. Martienssen, Phys. Zeits. 29, pp. 295-300, May I 5 th, 1928, Science Abstracts, August 25th, 1928, Vol. XXXI., Part 8, p. 59.4.) (6.344/9937 Germany.)

A mathematical analysis is given of a new method of damping out the oscillations of a gyro-compass. A small weight is placed on the edge of a disc 
attached to the moving system and parallel to the compass card. This weight is placed at the east side of the disc, and the small out-of-balance force produces an effective damping of the oscillations.

\section{Instruments for Testing Purposes}

The Escape of Heat from a Harmonically Oscillating Hot Wire. (R. S. Maxwell, M.A., B.Sc., Phil. Mag. and J. of Science, Vol. VI., No. 39, November, 1928, pp. 945-965.) (i I. I 5/9968 England.)

An electrically-heated platinum wire was mounted upon the prong of an electrically-maintained tuning-fork of frequency $\mathrm{n}$. The hot wire cooled, and superimposed upon the steady fall in resistance there was a periodic change, with a corresponding periodic change in the electric current. This current was analysed by means of a galvanometer, and was found to contain harmonics of frequency $2 \mathrm{n}, 3 \mathrm{n}$, and $4 \mathrm{n}$, in addition to the fundamental.

The escape of heat from the wire is due to the following factors:-

(r) The free convection effect, which is the same whether the wire is at rest or in motion, except in so far as it depends on the temperature of the wire, which is, of course, lowered when the wire is vibrating.

(2) The forced convection effect which depends upon the velocity of the wire through the air, and which gives rise to.

(a) The steady drop in resistance;

(b) Periodic changes of resistance of frequencies 2n, 4n, $6 \mathrm{n}$.

The magnitudes of $(a)$ and $(b)$ depend upon the temperature and diameter of the wire and the velocity of the cooling current.

(3) The effect due to the heating-up of the surrounding air which causes the fundamental and probably all the harmonics to be present.

A mathematical theory is developed, which is found to account qualitatively for the observed results.

Materials. (New machine for testing bearing materials, V.D.I., Part 3 I, August $4^{\text {th, }}$ 1928, p. Iog8.) (I 1.24/9948 Germany.)

The test piece, a small cylinder of I sq. $\mathrm{cm}$. cross section and $2.5 \mathrm{~cm}$. length, is pressed against a hardened steel ring and lubricated under certain standard conditions. The steel ring is heat insulated and the rise in temperature of the bearing metal specimen and the friction torque are recorded on a time basis. A series of bearing metals were tested below loads of $3^{\circ} \mathrm{kgs}$. and speeds of 4 metres per second showed small differences. With increased load and speed, the differences became more marked. The bearing metals of high tin content proved to be the best. Bearing metal with lead base containing graphite was the best under low load, but failed under heavy load.

\section{Metallurgy}

\section{Materials}

Steels Used in the Aircraft Industry. (H. J. French, paper read to American Iron and Steel Institute, Iron Trade Review, November Ist, I928, pp. I 105-i I08.) (10.12/9940 U.S.A.)

The paper gives the point of view of the steel maker in regard to demand for specially high quality material for aircraft construction. Tabular data are given of specifications of steels and the parts for which they are employed, in particular nickel, nickel-chromium steels for highly stressed parts, steels with high percentage of nickel or chromium for parts exposed to corrosion, and nickel-chromium steels with heat-resisting characteristics for exhaust valves. 
The Causes of Failure of Wrought Iron Chains. (Department of Scientific and Industrial Research, Engineering Research, Special Report No. 3.) (I0. $14 / 9956$ England.)

Experiments on chains taken from service of known history, together with a large number of laboratory experiments, have shown that the main cause of deterioration in service of wrought iron chains is the production on the links of a hardened skin by repeated small impacts. Annealing at a dull red heat causes recrystallisation and softening of the hardened skin, thus restoring the link to its normal ductile state. Normalising from $1,000^{\circ} \mathrm{C}$. produces the same result. The relative merits of annealing and normalising are fully discussed.

Notes on Riveting Treatable Aluminium Alloys. (Bohmer and Westtinning, Zeitschrift fur Melallkunde, No. 6, June, 1928, pp. 209-216.) (10.22/9963. Germany.)

The hot riveting of aluminium alloy causes a deterioration of the mechanical properties of the metal. Moreover, through the high conductivity the rivet itself cools very rapidly, and this causes changes of the structure of the rivet. Joints obtained by the hot riveting process show the presence of considerable internal stresses. In order to obtain consistent results the rivets must be placed in position cold. When riveting cold, considerable care is required that the pressure should be applied evenly and a special tool is described which is stated to have overcome initial difficulties.

Experiments on the Treatment of Electron Alloys. (K. L. Meisner, L.F.F., Vol. I., Part 3, 30/3/1928, Report No. 93 of the D.V.L., pp. 95-ror.) (10.22/9980 Germany.)

Among many obscure points the following rules stand out. A certain amount of the alloyed metal must be in permanent solution in the principal metal. The solubility of the alloy under fixed conditions must fall off with the temperature. These conditions are fulfilled in most of the electron alloys both $\mathrm{Mg}-\mathrm{Al}$. alloy and for an $\mathrm{Mg}-\mathrm{Zn}$. alloy, of which a large number have been tested in the I.G. Farben Industrie at Bitterfeld. Phase diagrams show the range of composition and temperature within which permanent solutions of $\mathrm{Al}_{3}-\mathrm{Mg}_{4}$ in $\mathrm{Mg}$, and of $\mathrm{Mg}-\mathrm{Zn}_{2}$ in $\mathrm{Mg}$ can exist. Further tables show annealing temperature and duration and corresponding Brinell hardness.

Three groups of alloys are thus dealt with-Group I, Magnesium-aluminium alloys; Group 2, Magnésium-zinc alloys; Group 3, Magnesium-aluminium-zinc alloys.

Of the alloys tested only two showed any notable increase in Brinell hardness with prolonged heat treatment.

The treatment of electron alloys is accentuated when the temperature of solution of either or both aluminium and zinc in magnesium is exceeded.

\section{Fatigue}

The Static Foundations of Fatigue Failure. (W. Kuntze, V.D.I., No. 42 , 20/10/28, p. 1488-1492.) (10.621/9946 Germany.)

The importance of behaviour under fatigue has led to many attempts to correlate properties, determined statically, with ultimate life under dynamic loading. The article considers the process of failure theoretically and the possibility of devising static tests which will give the information desired. 
The Nature of " Fatigue", in Materials. (K. Lante and G. Sachs, Zeitschrift des Vereines deutscher Ingenieure, August 25th, 1928, pp. II88-i I89.) (I0.62 I/9970 Germany.)

A series of nickel rods were tested under fatigue conditions, using the high frequency machine constructed by Schrenk, and the fatigue limits for various amplitudes were determined. In subsequent tests the rods were beat treated at $750^{\circ} \mathrm{C}$. for half an hour after a certain fraction of their normal life. In no case did the heat treatment increase the ultimate life of the specimen, and in most cases a decrease was observed. The author concludes that failure is due to a breaking up of the internal structure of the metal.

Recent Investigations on Mechanical Oscillations. (Prof. Dr. W. Hort, Zeitschrift des Vereines deutscher Ingenieure, No. 32, August itth, 1928, pp. I I 18-i I 22.) (I0.62 I/997 I Germany.)

A special committee of the V.D.I. deals with the theory of vibrations under three headings-(I) the loading of rotating parts in engines, (2) failures due to vibration, (3) the measurement of vibration, including noise. The committee has been in existence since 1924, and a series of papers has been published. Recently a meeting was held at Darmstadt, when papers dealing especially with vibrations of foundations were read. Vibration meters built by Geiger and Okhiusem are compared.

\section{Elasticity}

Two-Dimensional Problems in Elasticity. (M. Sadowsky, Z.A.M.M., Vol. VIII., Part 2, April, 1928, pp. 107-121.) (10.61/9972 Germany.)

The general plane problem is reduced to terms of two pairs of conjugate functions. The form of the solution depends on the statement of the boundary conditions: if given in terms of stress alone or of strain alone expansion in Fourier series gives a method of great generality. But if the boundary conditions are given partly in terms of stress and partly of strain, the analysis may introduce integral equations. problems.

Helicoidal symmetry in three dimensions may also give rise to soluble

The Structure of Wood in Relation to its Elastic Properties. (A. T. Price, M.Sc., Proc. Roy. Soc., A. Vol. CCXXVIII., pp. I-62.) (I0.61/9974 England.)

It is well known that the application of elastic theory to wood on the assumption that it is isotropic is a poor representation of the facts. In the present paper various degrees of anisotropy are assumed from experimental work and mathematical consequences are deduced. The results are compared with experiment in order to develop a workable method of estimating the various elastic coefficients. The structure of the wood is also examined, and a discussion is given of the relation between the structure of the wood and its elastic property.

In spite of the large differences between the stress system in a homogeneous body and that in a specimen of timber it is found that the overall deformations do not differ as much as might be expected. There is, therefore, some justification for the usual procedure of treating wood as a homogeneous material.

Some Problems of Shocks Transmitted in Bars and Plates. (K. Sezawa, Report Aero. Research Inst., Tokyo, No. 45, Vol. IV., Part 4, November, 1928, p.p. 83-1 47.) (10.6r/9975 Japan.)

Solutions are derived for the form of wave transmission from the equations of motion of bars or plates where the material is visco-elastic, subject to various boundary conditions. The following problems are discussed:- 


\section{PART I.}

A. A note on forced oscillations and free waves.

B. Diffusion of shocks from some disturbed origins.

C. Reflection and transmission of shocks of high frequency.

D. Anomalous dispersion of harmonic shocks of high frequency.

E. Transmission of shocks in tension and compression bars.

F. Remarks on the propagation of the statical deformation and on the failing section of a beam due to shocks.

\section{PART II.}

G. Diffusion of shocks in two dimensions from some disturbed origins.

H. Shocks transmitted along the edge of a plate.

I. Reflection and refraction of shocks at some discontinuities.

J. Scattering of shocks due to a circular obstacle.

K. Diffraction of shocks from a narrow slit.

L. Transmission of shocks of high frequency, the azimuthal variation being taken into account.

Although the author admits difficulties in relating the mathematical results to experimental facts, he claims that they indicate the amount of the stresses and the position of the points of failure.

\section{Corrosion and Dopes}

Accelerated Tests of Organic Protective Coatings. (Percy H. Walker and E. F. Hickson, Bureau of Standards Journal of Research, Vol. I., July, r928, No. I.) (Io. I $5 / 9953$ U.S.A.)

The equipment of the Bureau of Standards in accelerated tests of paints, varnishes, lacquers, bitumens, etc., is described.

A variety of organic coatings, subjected to a cycle of alternate exposure to light from an enclosed carbon arc, water spray and ozonised air, exhibited the same kind of decay as from exposure to the weather.

The difficulty of determining the relative condition of exposure tests is discussed, and methods are described for determining quantitatively, when the coating ceases to protect.

The Deterioration of Protective Coatings on Railuay Coaches. (O. Konig, V.D.I., September Ist, I928, p. I2I3.) (I0.15/9954 Germany.)

Experiments by the German railways show that paints with a linseed oil base give the best all-round results. Paints containing an acetate base and the asphalt lacquers were inferior, and the worst results were obtained with nitro-cellulose lacquers. In goods trains the worst corrosion was observed in trucks carrying coke, whilst trucks carrying lime were sound after 35 years. The life of the protective paint depends to some extent on the steel. Grood results have been obtained in America by adding copper to the steel before it is rolled into sheets.

Corrosion in Metal Sheets and the Effect of Crystal Surface Orientation. (Glauner and Glocker, Zeitschrift fur Metallkunde, Part 7, July, 1928, pp. 244-247.) (I0.27/9955 Germany.)

The same materials may possess very different rates of corrosion according as the crystals in the surface of the sheet are orientated in a definite manner or not. The rate of solution of a single crystal of copper is different for the crystal surface and for sections. The surface solution with acetic acid is greater and with hydrochloric acid less than the mean rate for all the crystallographic axes. A metal sheet consists of a large number of crystals orientated differently, and the rate of corrosion depends on the orientation. 
Preparation of Tungsten Carbonyl. (Andre Job, Comptes Rendus, No. I4, October ist, I928, ए. 564.) (10.44/994I France.)

At room temperature the carbonyl is crystalline, it decomposes at $100^{\circ} \mathrm{C}$., the metallic tungsten catehing fire in the air.

(Abstractor's Note,-This may be of interest in dope research.)

\section{Strength of Materials, Mathematical and Physical}

Compression and Buckling Tests in Light Metal.Tubes. (A. Schroever, 94th Report of the D.V.L., L.F.F., Vol. I., Part 3, 30/3/1928, p.p. Io2-I08.) (ro.6r/9977 Germany.)

Von Karman's method of computing the resistance to buckling of cylinders under central axial load is applied to comparatively short circular cylinders of alloys numbered $1,2,3,4$, and compared with test results.

The composition of the alloys is not given.

Tables and diagrams give elaborate comparisons of calculation with experiment.

Plastic Bucliling of Curved Cylinder Walls, etc. (J. W. Geckeler, Z.F.M.M., Vol. VIII., Part 5, October, I928, pp. 341-352.) (10.61/9976 Germany.)

In the experimental buckling of thin cylinders, disc plates, cheap metal reservoirs, etc., buckling under carefully applied stresses may take the form of waves in the metal. This periodicity of the physical phenomenon is investigated mathematically. The solutions have multiple values, and by selecting appropriate solution at least an approximate quantitative explanation can be given.

The differential equation is formed and solved. The periods are exhibited graphically, showing subsidence of the undulation.

The Use of the Yicld Point in Design and Acceptance Tests. (Kuhnel, r22612.32 , Zeitschrift des Vereines deutscher Ingenieure, No. 35, September ist, I928.) (I 1.24/9942 Germany.)

The upper yield point is affected by the cross section of the specimen under test. Cylindrical shapes give yield points considerably higher than those flat or angular shape, and the latter only show agreement with practice.

Note on the Recognition of the Yield Point of Steel. (Kunze and Sachs, Zeitschrift des Vereines deutscher Ingenieure, Part 29, July 21 st, 1928, pp. roII-IOI6.) (i 1.24/994.3 Germany.)

The variation in cross section of originally cylindrical specimen of steel was examined over the range from the yield point to ultimate fracture. The first evidence of deformation generally occurred near the end of the specimen or at a surface crack. With homogeneous material the reduction in area spread progressively along the specimen, the load remaining practically constant. When the new cylindrical shape of reduced diameter is reached, further increase in load produces a uniform extension of the whole specimen. The initial flow is attributed to the presence of a brittle constituent in the steel. This is especially marked in the case of silicon steels. The explanation of the phenomenon is complicated by the fact that a healing process is produced by ageing the specimen at low temperatures. The yield point is raised considerably by an increase in the rate of loading, a fact difficult to account for. 
Plastic Deformation of Crystals. (R. v. Mises Zeits. f. angew, Math. u. Mechanik, 8, pp. 161-185, June, 1928, Science Abstracts, Section A, Vol. XXXI., Part 11, 25/11/28, p. 839.) (10.6r/9945 Germany.)

A general theoretical survey of the mechanism of plastic deformation of crystals.

Intcmal Friction in Metals. (R. H. Canfield, Physical Review, September, I928, Vol. XXXII., p. 520.) (10.6I/9947 England.)

A tubular specimen of the metal is made the elastic control of a heavy pendulum bar. The system ean be set into forced vibrations, either bending or twisting the specimen, by a known periodic magnetic force-couple. The resonance amplitude and frequency, with the moment of the impressed force-couple, yield the ratio of the energy dissipated in one cycle to the energy of the vibration. The tubular form of the specimen enables the relation between dissipation and stress-amplitude to be studied in detail, at least for torsion. For normal (unfatigued) metal, the internal friction appears to be entirely associated with shear. This is not borne out in certain specimens of fatigued or overstrained metal; but the exceptions are easily accounted for.

Flattening of Steel Balls and Cylinders through Pressure Used in Measurements. (Prof. G. Berndt, Zeitschrift fur Instrumentenkunde, September, 1928, pp. 422-432.) (10.61/9969 Germany.)

The flattening of steel balls and cylinders has been investigated by Prof. Bochmann, of Dresden, and it was found that the numerical factor entering in the Hertzian equation required a reduction of 9.5 per cent. Previous experiments at the National Physical Laboratory, England, have shown the need of a reduction. varying from 4 to 16 per cent.

The Production of Extremely High Pressures (20,000 Atmospheres) and the Application in Science and Industry. (Journal de Physique et le Radium, Vol. IX., p. 55, 1928.) (10.62/9944 France.)

The high pressures are obtained hydraulically. On account of the importance of the work it is intended to establish a special high pressure laboratory. So far various modifications of carbon at high pressures and temperatures have been studied.

\section{Miscellaneous}

\section{Wireless}

Propagation of Electro-Magnetic Waves by Thin Wires of Various Conductivitics. (L. Bergman and G. Holzhorner, Ann. d. Phys., Vol. LXXXVII., Part 5, No. 2 I, 1928, pp. 653-676.) (13.5/9939 Germany.)

The general solution of Kelvin contains implicitly a term involving the diameter the distance from a neighbouring parallel wire, and the length of an ideal wave moving with the velocity of light and the conductivity.

In application this implicit term, along with higher terms, was neglected. In the present paper (following M. Mercier Ann d. Phys. 1923, and A. Hund Sc. papers of Am. Bureau of Standards, No. 49I, 1924) the author uses this term for comparison of the theoretical change of wave velocity with the ideal wave.

Measurements of the wave length were obtained by resonance methods to about one in ten thousand. The greatest discrepancy between observation and calculation was one in five thousand. (The distance between the wires (D) is 
omitted, and on calculating it from the data in Table 3 it appears that it varies from 7 to $77 \mathrm{~cm}$.-ABSTRACTOR's NOTE.)

The general agreement between experiment and mathematical theory shows that the latter is adequate.

Influence of the Earth's Atmosphere on the Propagation of Short Waves. (J. Fucks, Zeitschrift fur Hochfrequenztechnik, October, 1928, No. 4, pp. I 25-I29.) (I3.7/9979 Germany.)

Short electrical waves are dispersed by the intervening atmosphere by means of diffused reflection. From experiments on the audibility of short wave sending stations situated in America it is concluded that the effect of the atmosphere depends on the intervening pressure distribution.

A New Type of Loud Speaker without the Interposition of Mechanical Membranes. (Von Max Brenzinger und Friedrich Dessauer, Physik-Zeitschr. XXIX., I928, p. 654.) (13.21/9978 Germany.)

A very fine metallic wire is stretched centrally inside a slotted metallic cylinder with a potential difference of the order of Io,ooo volts, the wire being positive to the tube. A glow discharge takes place between wire and tube, the magnitude of which depends on the potential applied. If this system is placed in an electric oscillating circuit the variations in the electrical potential will cause changes in the electrical wind, and these in turn cause direct variations in the density of the air, thus producing sound waves. The same principle can be utilised in the construction of the microphone. Both instruments have been worked successfully.

\section{Civil Aviation}

Civil Aviation in the Light of Technical Development. (M. Haguenau, La Technique Aeronautique, No. 79, p. 72.) (I5.1/10009 France.)

The six private companies operating air lines in France experience difficulty in getting up-to-date commercial machines, as the manufacturers are concentrating on war types. The formation of a single aerial trust in France would reduce running expenses, and their combined orders would be sufficient to interest manufacturers in commercial design. Only in this way can the fierce foreign competition be met.

\section{Fire Prevention}

Studying Airplane Fires. (Anon., McCook Field, Dayton, O., Quarterly Natl. Fire Protect. Assocn., 22, 70-84 (1928), Chemical Abstracts, Vol. XXII., 20/10/28, p. 3992.) (I6.12/9952 U.S.A.)

A slow motion cinematograph record of actual tests made at Wright Field with old planes on a specially constructed runway show the exact location of the source of fire. Ignition systems are a minor cause compared with exhaust systems. Water-cooled exhaust and liquefied $\mathrm{CO}_{2}$ exhaust attachments were tried, but discarded in favour of air-cooled $\mathrm{Al}$ exhaust pipes provided with fins, designed to give a maximum surface temperature of $370^{\circ} \mathrm{F}$, and effectively lessening the proportion of fires. Fireproof partitions are recommended and progress on $\mathrm{CCl}_{4}$ extinguisher systems for airplanes is outlined. 


\section{Physiology of Aviators}

The Reduction of Oxygen in Air Breathed at Ordinary Atmospheric Pressure (Nitrogen Narcosis). (W. Kaiser, i I th Report of D.V.O., Z.F.M., Vol. XIX., Part 21, 14/1 I/28, pp. 489-493.) (19.2/996I Germany.)

A number of examples is given of handwriting of individuals subjected to artificial atmospheres deficient in oxygen by various percentages, and a brief account of the observed physiological effects.

\section{Medical}

The Effect of Low Partial Oxygen Pressure (Nitrogen Poisoning at Atmospheric Pressure). (W. Kaiser, Z.F.M., November 14th, 1928, No. 21, p. 489.) (19.2/9960 U.S.A.)

Experiments were carried out on human beings and animals, the oxygen concentration being reduced to 7 per cent. in the former and 2.8 per cent. in the latter case. Although no apparent changes in the blood circulation occur, there are serious physiological effects produced by a reduction of oxygen content at atmospheric pressure, differing from and persisting much longer than the effects produced at altitude.

\section{A coustics}

On the Acoustical Properties of Conical Horns. (Kozi Sato, Report of the Aeronautical Research Institute, Tokyo Imperial University, No. 42, September, 1928, Vol. IV., i.) (I5.2/9959 Japan.)

The intensity of sound as received through a conical horn with its axis set at different angles $\theta$ to the ray of sound, was measured by the Rayleigh disc. The distribution of the sound intensity as function of the angle $\theta$ mainly depends upon the wave length (or the frequency) of the sound, and only slightly upon the geometrical shape of the conical horn if the diameter of the opening be the same. If the wave length of the sound be short enough as compared with the diameter of the opening, the sound energy is considerable only for small values of $\theta$. On the contrary, if the wave length be long compared to the diameter, the sound energy is nearly equal for different values of $\theta$. 